\title{
New Epistemological and Methodological Criteria for Communication Sciences: The Conception as Applied Sciences of Design
}

\author{
Maria Jose Arrojo \\ Area of Audiovisual Communication, University of A Coruña, A Coruña, Spain \\ Email: maria.jose.arrojo@udc.es
}

Received 30 November 2014; accepted 15 December 2014; published 16 January 2015

Copyright (C) 2015 by author and Scientific Research Publishing Inc.

This work is licensed under the Creative Commons Attribution International License (CC BY). http://creativecommons.org/licenses/by/4.0/

(c) (i) Open Access

\begin{abstract}
There is a need for new epistemological and methodological criteria for communication sciences. This necessity is underscored by the important developments of communication in recent years, due to the information and communication technologies (ICT). Consequently, we should overcome interpretive schemes until now dominant, which see communication sciences only as social sciences (or even as it were a mere professional practice based on past experience). Hence, the reality of a new conception is required to specify communication sciences which are analyzed as applied sciences of design. Thus, the theoretical approach-in cognitive and processes-fits best to the reality of new communication phenomena. Within this novel framework, which deals with the current reality and the future projection of the communication sciences, the conception of them as applied sciences of design can follow several steps in order to present its characterization: 1) the scope proposed to do research regarding communicative phenomena; 2) communication science as applied disciplines (subjects focus to solve specific problems) that work on designs (they seek to enlarge the human potential communication); and 3) the new criteria that carry out this proposal about the epistemology and methodology of communication sciences (where the knowledge used in the designs is oriented toward artificial aims and, consequently, the processes will follow the lead of the designs in order to obtain the expected results).
\end{abstract}

\section{Keywords}

Communication Sciences, Applied Sciences, Sciences of Design, Sciences of the Artificial

\section{Introduction}

Recent decades have witnessed an enormous outpouring of work on communication sciences because of the 
massive amount of new communicative phenomena. Yet the epistemological and methodological criteria used for these new phenomena remain old: they are commonly focused on the traditional approach of communication sciences as social sciences. This approach is clearly insufficient to deal with all the contributions made to this realm by the information and communication technologies (ICT). The new communicative phenomena, in which Internet plays an important role, require the criteria of the sciences of the artificial. This can lead to a new conception of communication sciences as applied sciences of design ${ }^{1}$.

Following the new characterization of economic phenomena within the sphere of the applied sciences of design, the emphasis is no longer on the social dimension of these phenomena but rather on the enhancement of human communication. Thus, these sciences of the artificial seek to enlarge the human potential communication $^{2}$. Consequently, the task of these applied sciences is to solve specific problems in a practical domain, and the focus moves toward aims, processes, and results. In this regard, the analysis requires taking three main aspects into account: i) the scope of research proposed for communication phenomena in terms of designs; ii) the processes of communication sciences as applied disciplines that are seeking to expand the human communication potential; and iii) the new epistemological and methodological criteria used to grasp the recent communicative results.

\section{Scope Proposed for the New Scientific Research}

So far, the dominant trend in the study of communicative phenomena has emphasized the realm of the social sciences. Sometimes, the vision has been as mere communicative patterns in form of "techniques" ${ }^{3}$. At the same time, the instrumental role of technology has been highlighted as a vehicle that enables progress. The first approach - the social perspective-emphasizes the need of human beings to interact and communicate with our social environment. The second approach—-the technological one-reflects the way to expand that inherent human characteristic of relationship. In fact, communication processes are increasingly dependent on technological developments.

However, these two approaches-the social-scientific perspective and the technological-instrumental viewpoint-are insufficient to adequately grasp the scientific articulation of these disciplines. With just the two of them, we are not able to reflect neither the object of study that communication sciences address nor the type of problems they seek to solve. The object and the kind of problems require a new epistemological and methodological framework. The new approach is in the sciences of design as applied sciences, which is followed by a scientific application ${ }^{4}$. The approach of communication sciences as applied sciences offers more relevant elements than the usual options mentioned. It is also a more comprehensive approach than the previous ones, both in structural and dynamic terms. Within this new realm it is worth pointing out the components that configure the communication sciences.

Initially, there is a dual starting point for these disciplines: the social and the artificial. Because communication sciences-as it is also the case with another disciplines, such as economy-are driven by two different key aspects. On one hand, it has a social component attach to them, which is inherent (the natural capacity of human beings of relationship); and, on the other hand, it has an artificial ingredient, which is built by human beings in order to broaden and extend human possibilities (Gonzalez, 2012a). Hence, communication sciences have a fork in its origin: a) to study the human need of communication, and b) to analyze how these communicative possibilities expand, reaching goals that go far beyond the basic needs of social communication.

This second task is done through artificial means. Some results are obtained by drawing some designs, which use specific technologies as a way to obtain specific goals. This implies that communication sciences are in the realm of the artificial by its aims, processes, and results. Hence, communication sciences elaborate designs that are aimed at solving specific problems, which are well defined in space and time. Therefore, they are applied science because they solve specific issues in a practical domain (Niiniluoto, 1993). They have in themselves an

\footnotetext{
${ }^{1}$ Regarding the characteristics of these applied sciences of design, see Bereijo, 2011, and Gonzalez, 2012.

${ }^{2}$ The features of the applied sciences in general are in Niiniluto, 1993. The sciences of design are a land of the sciences of the artificial, see Simon, 1996.

${ }^{3}$ The concept of "technique" is different and prior to the notion of "technology", cf. Gonzalez, W. J., "The Roles of Scientific Creativity and Technological Innovation in the Context of Complexity of Science”, in W. J. Gonzalez, (Ed.), Creativity, Innovation, and Complexity in Science, Netbiblo, A Coruña, 2013, pp. 11-40.

${ }^{4}$ The difference between "applied science" and "application of science" was described in 1993 by Niiniluoto. On this topic there is a whole section in Gonzalez (2013) pp. 11-40.
} 
empirical modus operandi. They also have a high degree of complexity insofar as they have a social as well as an artificial aspect (Gonzalez, 2008b).

If we go further into the roots of the communication sciences as applied sciences of design, then there are several steps to be taken into account. Firstly, we have to identify the characteristic features of the science. Secondly, we have to specify the different ways in which science is diversified. Thirdly, we have to find the right place for communication sciences within the current scientific categories. Doing so, we will get two commitments, since - in addition to promoting its internal configuration as scientific knowledge-we will be defining where the communication sciences stand in the realm of knowledge.

\subsection{Characteristic Features of Science and Its Presence in Communication}

To characterize the communication sciences as scientific disciplines, requires a first step, which is to take into account the characteristics of a science. a) Science has a specific language, it carries terms with a sense and a well-defined reference. b) It has its own structured theory, which in case of applied sciences is aimed at solving specific problems. c) Science employs a rigorous type of knowledge. d) Science has characteristic methods. When it comes to applied sciences, science seeks to solve specific problems. e) Science is configured as a human activity of a social nature: a dynamic reality permeate by historicity. f) Science is related to a set of values, some internal (consistency, simplicity, objectivity, versatility, etc.) and some external (social, cultural, economic, etc.). g) It is ethically evaluable, both from an internal perspective (reliability, honesty, etc.) and from an external perspective (science is not detrimental to the user, provides accurate information for decision-making, etc.) (Gonzalez, 2005, 2013; see also Arrojo, 2007).

General philosophy and methodology of science deals with the study of these characteristic features of a science. It does so from a broader perspective: it looks for valid statements that work for every science. Meanwhile, special philosophy and methodology of science reflects on the specificity of each science. Then, there are two aspects of this second consideration: I) the broad perspective, which seeks the links between the general science (or a group of sciences) and the specific discipline that is studied; and II) the restricted viewpoint, which is focused to specific problems and it is developed by specialists in each discipline (Gonzalez, 2012b). In the case of communication sciences, we can find the two aspects of special methodology of science. It can be seen in the relationships with general features of a science or groups of sciences. Also, communication has its own specialists for methodological issues that are distinctive to this sphere.

Within the second aspect to be considered here-the different modes in which science diversifies-is the distinction between the formal sciences and empirical sciences. Here, regarding this distinction, communication sciences belong to the second group. The reason is clear: the "sciences of the artificial" and, among them, the sciences of design are in the domain of the empirical sciences. It is the field of the human-made that can made empirical statements (Simon, 1996, 2001). The sciences of the artificial commonly use designs. They are focused on aims, processes, and results of human activities (economics, documentaries, communicative, etc.), which can be tested by observation and experimentation.

In addition — as a third step to find the right place for communication sciences—is necessary to consider that scientific research is not always carried out in the same way. Certainly, we can make a distinction between basic science and applied science depending on aims and processes (Niiniluoto, 1995a, 1995b). The primary aim of any basic science is to expand the knowledge of reality by means of explanation and prediction. Thus, basic sciences specify the events (or facts of the world) that occur and seek generalizations to describe collections of phenomena (Simon, 2001: 32). Meanwhile, applied science is oriented towards resolving specific problems with a domain. It follows three moments in this regard: aims, processes, and results. Applied science includes predictions and prescriptions.

According to Simon, "Laws connecting sets of variables allow inferences or predictions to be made from known values of some of the variables to unknown values of other variables. Inferences and predictions can be used, in turn, to invent and design artifacts (e.g., arches) that perform desired functions (support the weight and other stresses placed on them), or to anticipate and adapt to future events on the basis of knowledge about the present and past. At the times the predictions are realized, the new data can be used, of course, to test whether the laws continue to hold" (Simon, 2001: 32; see also Gonzalez, 2007).

Following these features, communication sciences can been seen as applied sciences: they make predictions regarding the possible future, and they propose prescriptions to solve specific problems. The traditional view of communication sciences, which is still dominant, is to consider them as social sciences. This view recognizes 
the instrumental support of information and communication technologies (ICT).

But there is an increasing tendency to see communication sciences cannot be confined to a sociological study or considered just because of their technological constraints. It is clear that there is now an increasingly use of ICT in the communication sciences. However, we need the perspective of sciences of the artificial to characterize communication sciences today, which includes to understand them as applied sciences of design. In this respect, communication sciences can solve specific problems starting from the use of designs. This is done based on a set of ends, using the means that technology make available.

\subsection{Epistemological and Methodological Framework of Communication: From Social Sciences to Sciences of the Artificial}

Under these new epistemological and methodological criteria, communication sciences are a twofold kind of science. On the one hand, they have components of social sciences, insofar as their concerns to human needs; and on the other hand, they are sciences of the artificial, insofar as they work with designs, where there is a high degree of dependence on technologies (Gonzalez, 2008b; Arrojo, 2012). The social sciences components come from the inherent human need to interact with others and their environment (Backhouse \& Fontaine, 2010). These links are based on intentional human actions, which take place in a social environment. Thus, these disciplines analyze the origins, development, and consequences of human actions related to the social role of communication (Bishop, 2007), within this sociocultural environment where such communication takes place.

At the same time, communication sciences enlarge the communication possibilities of the human beings, because they offer us new options. They allow going further than the immediate vital horizon to reach the "global village". The constant expansion of the communicative possibilities, which are due to human designs, are studied by these disciplines as sciences of the artificial. Communication sciences give a scientific perspective to a human activity based on professional practice. Then, they broaden the huge possibilities of communication reaching new commitments by using the available tools of technology (Arrojo, 2008).

In this regard, communication sciences need the contribution of technology in order to achieve their aims. Technology is by definition a creative transformation of reality (Gonzalez, 2005, 2013). Therefore, it provides the device that is the instrumental support to achieve the selected aims. Technology gives the operative channels that lead the communicative content. It does so using its different channels as image, sound, signal, etc. When a new communicative phenomenon starts, there is commonly a technological device that operates to look for some chosen aims (Arrojo, 2007, 2013). These aims have been previously chosen by the professionals, those working on the media. After these aims, there are some processes, which are indispensable to achieve the expected results.

These processes are made based on a design that relies on predictions to trace the possible future. Thereafter, it is prescribed with patterns of kind of action to solve a specific problem defined in space and time. Thus, there are a few goals and designs to achieve those goals along with guidelines for action, as it is typical of applied sciences of design (Gonzalez, 2007). The communication sciences are then displayed as science of the artificial: we are in a field of the "human-made", both in terms of aims and processes, and when it comes to results (Gonzalez, 2008a).

\section{Communication Sciences as Applied Sciences of Design}

Within the sciences of the artificial, communication sciences are a clear example of applied sciences. i) Its subject is not in nature but in the field of the artificial: the transmission channels, formats, programs, interactive content, slots, etc. ii) They are oriented to solve specific problems of communication; which includes looking for patterns of action, strategies that are directed towards achieving a result. The targets may be oriented towards reaching the widest possible audience, the best program quality, or the optimal economic results. iii) These sciences are evaluated in terms of usability and usefulness of processes and results (Arrojo, 2007).

This scientific-applied dimension of the "communication sciences" highlights that the field of study cannot be reduced to the perspective of the social sciences. Moreover, there is a net expansion of the initial possibilities of communication. This is encouraged by the information and communication technologies (ICTs). All the media uses ICTs to enable the creation and dissemination of increasingly elaborated messages. Hence, the media expands our communication skills, those that are natural to us as social beings, those we have inherent to us as human beings. They are artificial factors in communication sciences and bring an increasingly sophisticated as- 
pect to them. This practical aspect has been articulated in terms of the science of design, which considers aims, processes, and results (Arrojo, 2013).

\subsection{The Communication as a Science of Design}

Initially, as they are social sciences, communication sciences deal with a type of intentional human actions that take place in a social environment. These disciplines analyze the origins, developments, and consequences of human actions related to the social role of communication (Bishop, 2007). In this respect, they are sciences that consider the socio-cultural environment where communication takes place (Arrojo, 2012), where the language —in its various specifications-plays a key role.

Increasingly, communication sciences expand human possibilities of subjective report: they look for more sophisticated goals. Their contents need the use of the technology, which gives tools and elements to broadcast. After a creative transformation of reality (Gonzalez, 2005), technology offers a device (radio, television, Internet, etc.) serving as an instrumental support for the transmission of communicative content, and to obtain the selected aims (Gonzalez, 2007). The communication sciences shape the design of a communicative phenomenon that takes place based on specific aims that require an adequate technology (Arrojo, 2012).

These constant communicative field extensions, which are due to human designs, are studied as the sciences of the artificial. In this regard, communication sciences give a scientific perspective to a human activity based on professional practice as well as expanding the existent possibilities, insofar as they work with designs (Niiniluoto, 1993). Thus, as they are sciences of the artificial, they have three relevant features: a) these communications disciplines have new aims that appear in their designs; b) they use some processes for achieving those goals; and c) they can obtain concrete results. In this case, we can say that communication sciences fit into the sphere of sciences of design (Gonzalez, 2007).

\subsection{Communication as Applied Science}

Within the set of scientific disciplines, communication sciences are applied sciences, insofar as they are aimed at solving specific problems (Niiniluoto, 1995a). Thus, they are aimed at addressing specific issues within a diverse practical domain, as it is the human communication. On one hand, communication sciences deal with the structural aspects of communication phenomena. They research the teleological function of communication, i.e., the task of providing targeted communication to specific aims. On the other hand, they analyze their dynamic aspects, those that are concerning the changes that occur in human communication. These changes are due to changes that occur in the environment and lead to variations to fit the changing environment (Arrojo, 2012).

This dynamic aspect of communication sciences initially focuses on three successive elements of the "internal" to the communicative phenomenon: aims, processes, and results. These components comprise a working knowledge geared towards achieving goals. It is, therefore, a dynamic of applied sciences of design (Niiniluoto, 1993), where the purpose modulates the rest of the investigation process. The communication sciences work with some designs that are geared towards specific communication aims. These aims are deliberately chosen to expand the human communicative potential. Thus, communication sciences, understood as applied sciences, research the human ability to solve specific communication problems (Arrojo, 2012). By doing so, they have to consider the "external" communicative phenomenon (legal, economic, etc.).

According to Herbert Simon, when we talk about "the sciences of the artificial", knowledge entails action (Simon, 1996a). As they are applied sciences of design, communication sciences help to solve present and future problems. So, as applied sciences, they combine prediction with prescription (Simon, 1990; Gonzalez, 1998). To that purpose, they study what solutions have been appropriate among all who have been used by the professionals. After that, they seek to create scientific guidelines for action (Arrojo, 2012). First they deal with "internal" aspect to the communicative phenomena and, then, they take into account the "external" factors that influence and modulate the possibility and extent of the communicative phenomena.

\section{Epistemological and Methodological Criteria of Communication as a Science}

For the epistemological and methodological criteria of communication as sciences, we have to consider two main aspects. First, communication has to be analyzed from the internal dimension of science, which is basedfrom the instrumental point of view—on the support given by technology. Second, we have to study communi- 
cation from the external perspective, which is due to environmental factors related to the phenomena at stake. These aspects can be considered successively as these disciplines are sciences, applied sciences, and part of the group of the sciences of the artificial (specifically as sciences of design).

For the study of communication as a scientific activity, we must analyze the epistemological and methodological criteria through two pathways: internal and external, which deal with the components of the cognitive contents and the processes used. But again, it is worth pointing out that the "internal" criteria of communication finds different aims, mainly in the cognitive sphere. Insofar as communication sciences are applied sciences, they seek to solve practical problems in a particular area (Niiniluoto, 1993, 1995b). In order to achieve this task, which requires setting priorities, they require an instrumental technological component. Hence, communication gets it aim when it uses the right device to perform certain operational functions for the remote transmission of content (Gonzalez, 2008a: 170-171).

As communication sciences are applied sciences of design, they are not limited to the content of knowledge (explain and predict). In addition, the design plays a fundamental role in both cognitive content and the practical uses. Unlike any basic science, communication sciences as applied sciences seek practical guidance of the scientific knowledge (Niiniluoto, 1993: 6). But, besides that internal aspect of science, which requires the instrumental use of technology, there is an external component that modulates both cognitive content and the practical uses. In this respect, communication involves values such as: social, ethical, political, legislative, economic, etc. These values have a great impact on communication processes that depend on the available opportunities that technology and the current economic, legal, and social conditions offer (Arrojo, 2007).

Each of these two aspects (internal and external) affect the aims, processes, and results of communication sciences. It is worth pointing out three successive epistemological levels: a) the rationality of science as such, which is shared by the various scientific fields; b) the rationality of a particular discipline, which corresponds to the specific scientific activity; and c) the rationality of the agent that makes decisions (Gonzalez, 2003). In this epistemological analysis, Wenceslao J. Gonzalez focuses on the case of another science of design-economics-highlighting the human cognitive ability and the role of agents with their decision-making.

On this basis, we can distinguish three different levels of epistemological rationality in the sciences of the artificial. i) The rationality given by the fact that it is a kind of science, which differentiates its research from other human activities such as technology. ii) The rationality that is characteristic of the specific discipline, which in this case affects the communication designs, communicative processes, and results. iii) The rationality of the actors involved in the field of these sciences, which includes their criteria when making decisions (Gonzalez, 2008a: 172). Thus, there may be different uses of rationality that influence the achievement of the set of goals considered (Gonzalez, 2003: 75-76).

These three epistemological levels can be found in the communication sciences as applied sciences of design. The first feature is the common rationality of being a science, which varies according to the different scientific disciplines. The second aspect can be seen on the rationality of communication as such, i.e., a scientific activity that is connected with other disciplines, both in the social sphere as well as the artificial realm. The third factor of rationality is associated with the decisions of the agents. This feature includes the communicative rationality of the agents within their companies.

Regarding rationality in the communicative sciences, we can think of Herbert Simon's approach to rationality as bounded. Without addressing specifically the communication sciences, and from a conception of human rationality of the agents, he wanted to emphasize that agents have a bounded rationality. " 1 . In a broad sense, rationality denotes a style of behavior (A) that is appropriate to the achievement of given goals, (B) within the limits imposed by given conditions and constrains. 2. In particular contexts, (A) and (B) of the definition may receive more exact specification” (Simon, 1982 [1964]: 405; see also Simon, 1972: 161). Within this framework, bounded rationality is not a maximizing rationality in the sense of being able to get the best possible. Moreover, it is empirically testable. Thus, it is worth pointing out the observation of behavior of the communicative agents in the development of their own behavior. This behavior can be tested empirically, rather than simply accept a previous theory, formulated in previous considerations.

\subsection{The Epistemological Approach: Instrumental Rationality and Evaluative Rationality}

Simon insists on the empirical approach of the rationality, because he looks at rationality with a descriptive point of view: how agents make decisions, rather than follow the prescriptive look: how agents should chose. 
There are other authors, such as Nicholas Rescher or Reinhard Selten, who offer features that complete the analysis of human rationality and include more real and actual elements to it. Hence, they lean more towards the prescriptive view. Rescher approaches it from a philosophical perspective and Selten from an economic viewpoint.

Rescher distinguishes three types of rationality based on the object of rational deliberation. 1) Cognitive rationality, which is anything that may be believed or accepted both in the formal and empirical knowledge. 2) Practical rationality, which makes decisions about the actions to take. 3) Evaluative rationality that dictates what is to be preferred or valued (Rescher, 1988: 3). This set of types of rationality affects the communication as human phenomenon, where we can see cognitive, practical and evaluative components.

On the role of the rationality of the agents, insofar as there is choice and decision making, we should point out three different dimensions of rationality: i) the epistemic or cognitive, where rationality is an attribute of content accepted by the agent; ii) the practical, which is being able to achieve the optimization of their actions within their situational constraints; and iii) rational evaluation, where the agent has to make decisions about appropriate uses. This set of possibilities directly concerns to the application of communication sciences: the agents of the professional firms are the ones that have to make decisions about what to do in each case.

Simon's approach takes into account the cognitive rationality and practical rationality. But rational evaluation does not appear as such in his work, since Simon does not assume a rationality of ends but only a rationality of means (Gonzalez, 2003: 71). Meanwhile, rational evaluation does appear in Rescher: "Rationality hinges not on what we do want, but on what we ought to want—on what ends we are well advised to have in the actually prevailing circumstances" (Rescher, 1988: 112). Consequently, "rational choice is a matter of opting not for what is preferred, but for what is preferable” (Rescher, 1988: 112).

Following Rescher's general approach to rationality, its position can be used to focus the rationality of science. This task can also be done in three different levels, which correspond to three successive philosophical realms: epistemology and methodology of science, when the emphasis is on the cognitive component and, consequently, on the processes; ontology of science, when the activity itself of researching is highlighted; and ethics of science and axiology of research, when the determining factor are the ends - modulated by values, which includes ethical values.

On the other hand, if the attention is placed on Simon's perspective, his position focuses exclusively on the rationality of means. "We see that reason is wholly instrumental. It cannot tell us where to go; at best it can tell us how to get there. It is a gun for hire that can be employed in the service of whatever goals we have, good or bard" (Simon, 1983: 7-8). Therefore, he thinks the rationality should not evaluate the ends or aims because he see rationality as merely instumental. It doesn't seem to be aware of the rationality of ends (Simon, 2003: 60), which leads us to choose the preferable rather than merely selecting the preferred ${ }^{5}$.

Although Selten is influenced by Simon, in this respect he is most accurate than him. Even when Selten accepts the instrumental rationality, he also supports the presence of an evaluative rationality. Therefore, unlike Simon, Selten argues that we can evaluate the ends and not merely the means. Basically, Selten assumes that rational choice is dictated not by what is preferred, but what it is preferable. He, therefore, accepts the rationality of means and the rationality of endsare two aspects of the economic rationality (Selten, 1990: 656; see also Selten, 1998, 2001).

It seems to me that it is worth using these approaches to analyze the field of communication sciences in the proposed sense: as applied sciences of design. This is because in communication there is a rationality of ends (or evaluative rationality) — we have to select what we really want to communicate—and, to get to the goal, there is a rationality of means (or instrumental) in the selection of the appropriate means for its intended end (Rescher, 1988). This affects on how we create the applied science, but also to the application of science itself.

As a matter of fact, the agents specialized in communicative production contribute to design and to shape the final product. This product is the result of the combination of all the ideas of the people involved in its preparation. This idea requires prediction and prescription. It allows associating the act of communication to a prescription. Within the prescription can be "planning" or, what is the same, calculation and distribution of space and time in communication. The reason is clear: in order to achieve the expected results, the prescription need to follow some guidelines through different processes (Gonzalez, 1998). Any prescription is based on a prediction of the future. Thus, the prescription is based on a statement about what could possibly happen (in a short, me-

\footnotetext{
${ }^{5}$ This has direct consequences for television programming, which is the application of the Science. TV professionals need to know how to choose the preferable, under a set of values, rather than merely select what is preferred, with the consequent stagnation.
} 
dium, or long term). Then the patterns of prescription can be translated into planning, which includes the direction of the action in time and space (Gonzalez, 1996).

Let me stress that it is important to point out that the communication does not only stay in the rationality of means or instrumental, since it also involves an evaluative rationality or rationality related to ends. Commonly, any communicative phenomena are nowadays based on the decisions made on the communicative production. This is done under professional standards, even when the decisions may be conditioned to a greater or lesser degree by issues unrelated to the communicative content (cultural, social and economic conditions, policies, etc.). In that case, they will form an actual result from many possible outcomes (Rescher, 1999: 79, 80, 82, 172).

So, we can see a rationality of means or instrumental — where the best means are used to achieve the intended end-and a rationality of ends or evaluative, leading to choose the appropriate purposes for the activity developed (Gonzalez, 2003: 71). In other words, the communication process—not just aims-involves an evaluative rationality, which selects a preferred aim among many other possible (Rescher, 1999). In addition, to reach the desired end, the phases of the communication process respond to a particular form of communication, which require knowing how to use the available technological resources. This is a rationality of means or instrumental rationality, which is used for the selection of appropriate means for its intended end (Rescher, 1988).

\subsection{The Methodological Approach: The Problem of Methodological Universalism in the Face of Complexity}

As noted above, we can distinguish three main levels of scientific research: i) science in general (especially the empirical disciplines); ii) a group of sciences, such as natural sciences, social sciences and the sciences of the artificial; and iii) the specific sciences, such as biology, economics, computer science or communication sciences. There is a tendency to think of the possible existence of a methodological universalism in science, which would be valid for all sciences. This stream of thought tries to find a unit in science from the research processes. These levels can take advantage of the various options of a methodological universalism in scientific research ${ }^{6}$.

Among the three different levels of scientific research - the general field, on group, and the specific one-, the proposed methodological universalism are sometimes explicit (e.g., in the ideal of a unified science of logical positivism), while, in other cases, the approach is rather implicit (e.g., in the case of some evolutive perspectives where their point of view may sometimes have expanded beyond the initial expectations). Both orientations-explicit and implicit—have serious problems from the methodological point of view (Gonzalez, 2012b).

Moreover, these varieties of methodological universalism could lead to a methodological imperialism. They can do it depending on the extent of the scope of their subject area (its "natural" region) and because of its extension to other thematic areas (occupying other territories). The methodological imperialism could be regarded as the general methodology of science. This could be the case, for example, of the development of a methodological proposal based on logical reasons. This means assuming the idea of the universal validity of logic for developing science. But it is also possible to think of a methodological naturalist type of imperialism, a position based on, for example, evolutionary Darwinian approaches (Gonzalez, 2008a).

In the methodological universalism we could be facing the case of instrumental rationality, which is based on the belief of a certain attributes and the recognition of their correctness (Bicchieri, 1992). A clear example is the instrumental rationality proposed by Simon (1983: 7-8), where what matters is the success in the use of means. Such an approach ignores the evaluative rationality: first, the ends are given or assumed as given-they are not evaluated as such-; and, second, the agent is always instrumentally rational. That is to say, he or she must make practical decisions about means, depending on the ends already given.

The ideal of a unified science-logical positivism—can be seen as a methodological universalism rooted in logical reasons, where physics are presented as a key science in the field of empirical sciences (Carnap, 1932, 1995). Another version of an alleged methodological universalism is the acceptance of the "scientific method" as such, i.e., a method that serves for all sciences of empirical type. But any kind of methodological universalism does not resist an historical review. In addition, it cannot be accepted a universal method to deal with all the possible object of scientific research.

In addition, the idea of a methodological imperialism is also problematic. To begin with, all possible methodological imperialism must necessarily be temporary, since, at any time, another conception of the method could be developed to replace the dominant methodological perspective (Gonzalez, 2012b: 161). Furthermore,

${ }^{6}$ An analysis of these options of methodological universalism and their critical observations is available in Gonzalez (2012b). 
the continuity of the methodological principles seems almost impossible due to the critical attitude of science, which involves a constant review of processes in order to achieve new aims (Niiniluoto, 1984). However, the main obstacle of methodological universalism is the existence of the complexity. The communication sciences viewed as applied sciences of design are intersected by two different types of complexity: the one that looks after its structural component and the one that looks after the dynamic dimension.

Both the structural complexity and dynamic complexity have their own epistemological and ontological elements (Gonzalez, 2012c). This complexity—structural and dynamic, epistemological and methodological-affects the objects, problems and methods of some sciences. In addition, complexity is relevant for the aims, processes, and results of applied sciences such as communication sciences. Thus, depending on the objects and problems to be researched, applied sciences use a variety of methods. Consequently, there is not one single research method to be used all the time in communication sciences. That is the ground for new epistemological and methodological criteria to be used in the analysis of communication sciences. This feature of complexity goes in line with another relevant trait: the scientific methods used progressively in many disciplines tend to go towards a greater multidisciplinary and interdisciplinary.

\section{Acknowledgements}

I would like to thank Professor Wenceslao J. Gonzalez, who gives me scientific guidance, for his never ending support.

\section{References}

Arrojo, M. J. (2007). Caracterización de las Ciencias de la Comunicación como Ciencias de Diseño: De la racionalidad científica a la racionalidad de los agentes. In W. J. Gonzalez (Ed.), Las Ciencias de Diseño: Racionalidad limitada, predicción y prescripción (pp. 123-145). A Coruña: Netbiblo.

Arrojo, M. J. (2008). La configuración de la televisión interactiva: De las plataformas digitalesa la TDT. A Coruña: Netbiblo.

Arrojo, M. J. (2012). Objetivos, procesos y resultados en Ciencias de la Comunicación desde la perspectiva de la Ciencias de la Complejidad. In W. J. González (Ed.), Las Ciencias de la Complejidad: Vertiente dinámica de las Ciencias de Diseño y sobriedad de factores (pp. 123-145). A Coruña: Netbiblo.

Arrojo, M. J. (2013). Communication Sciences as Sciences of the Artificial: An Analysis of the Digital Terrestrial Television. In H. Andersen, D. Dieks, W. J. Gonzalez, Th. Uebel, \& G. Wheeler (Eds.), New Challenges to Philosophy of Science (pp. 325-336). Dordrecht: Springer. http://dx.doi.org/10.1007/978-94-007-5845-2_26

Backhouse, R., \& Fontaine, Ph. (Eds.) (2010). The History of the Social Sciences since 1945. Cambridge: Cambridge University Press. http://dx.doi.org/10.1017/CBO9780511845260

Bicchieri, C. (1992). Two Kinds of Rationality. In N. de March (Ed.), Post-Popperian Methodology of Economics (pp. 155-188; especially, 161-162). Boston: Kluwer.

Bishop, R. C. (2007). The Philosophy of Social Sciences. London: Continuum.

Carnap, R. (1932). Die physikalische Sprache als Universalsprache der Wissenschaft. Erkenntnis, 2, 432-465. [English Translation by Max Black. Carnap, R. (1995). The Unity ofScience. Bristol: Thoemmes Press.] http://dx.doi.org/10.1007/BF02028172

Gonzalez, W. J. (1996). On Theoretical Basis of Prediction in Economics. Journal of Social Philosophy, 27, 201-228. http://dx.doi.org/10.1111/j.1467-9833.1996.tb00261.x

Gonzalez, W. J. (1998). Prediction and Prescription in Economics: A Philosophical and Methodological Approach. Theoria, 13, 321-345.

Gonzalez, W. J. (2003). Racionalidad y Economía: De la racionalidad de la Economía como Ciencia a la racionalidad de los agentes económicos. In W. J. Gonzalez (Ed.), Racionalidad, historicidad y predicción en Herbert A. Simon (pp. 65-96). A Coruña: Netbiblo.

Gonzalez, W. J. (2005). The Philosophical Approach to Science, Technology and Society. In W. J. Gonzalez (Ed.), Science, Technology and Society: A Philosophical Perspective (pp. 3-49). A Coruña: Netbiblo.

Gonzalez, W. J. (2007). Configuración de las Ciencias de Diseño como Ciencias de lo Artificial: Papel de la Inteligencia Artificial y de la racionalidad limitada. In W. J. Gonzalez (Ed.), Las Ciencias de Diseño: Racionalidad limitada, predicción y prescripción (pp. 41-69). A Coruña: Netbiblo. http://dx.doi.org/10.4272/978-84-9745-212-0

Gonzalez, W. J. (2008a). Rationality and Prediction in the Sciences of the Artificial: Economics as a Design Science. In M. 
C. Galavoti, R. Scazzieri, \& P. Suppes (Eds.), Reasoning, Rationality, and Probability (pp. 165-186). Stanford, CA: CSLI.

Gonzalez, W. J. (2008b). La televisión interactiva y las Ciencias de lo Artificial. In M. J. Arrojo Baliña (Ed.), La configuración de la televisión interactiva: De las plataformas digitales a la TDT (pp. XI-XVII). A Coruña: Netbiblo.

Gonzalez, W. J. (2012a). La Economía en cuento Ciencia: Enfoque desde la complejidad. Revista Galega de Economía, 21. Spanish Version. http://www.usc.es/econo/RGE/Vol21_1/castelan/bt1c.pdf

Gonzalez, W. J. (2012b). Methodological Universalism in Science and Its Limits: Imperialism versus Complexity. In K. Brzechczyn, \& K. Paprzycka (Eds.), Thinking about Provincialism in Thinking, Poznan Studies in the Philosophy of the Sciences and the Humanities (Vol. 100, pp. 155-175). Amsterdam/Nueva York: Rodopi.

Gonzalez, W. J. (2012c). Las Ciencias de Diseño en cuanto Ciencias de la Complejidad: Análisis de la Economía, Documentación y Comunicación. In W. J. Gonzalez (Ed.), Las Ciencias de la Complejidad: Vertiente dinámica de las Ciencias de Diseño y sobriedad de factores (pp. 7-30). A Coruña: Netbiblo.

Gonzalez, W. J. (2013). The Roles of Scientific Creativity and Technological Innovation in the Context of Complexity of Science. In W. J. Gonzalez (Ed.), Creativity, Innovation, and Complexity in Science (pp. 11-40). A Coruña: Netbiblo.

Niiniluoto, I. (1984). Is Science Progressive? Dordrecht: Reidel.

Niiniluoto, I. (1993). The Aim and Structure of Applied Research. Erkenntnis, 38, 1-21. http://dx.doi.org/10.1007/BF01129020

Niiniluoto, I. (1995a). Approximation in Applied Science. Poznan Studies in the Philosophy of the Sciences and the Humanities, 42, 127-139.

Niiniluoto, I. (1995b). The Emergence of Scientific Specialties: Six Models. Poznan Studies in the Philosophy of the Sciences and the Humanities, 44, 211-223.

Rescher, N. (1988). Rationality: A Philosophical Inquiry into the Nature and the Rationale of Reason. Oxford: Clarendon Press.

Rescher, N. (1999). Razón y valores en la Era científico-tecnológica. Barcelona: Paidós.

Selten, R. (1990). Bounded Rationality. Journal of Institutional and Theoretical Economics, 146, 649-658.

Selten, R. (1998). Features of Experimentally Observed Bounded Rationality. European Economic Review, 42, 413-436.

Selten, R. (2001). What Is Bounded Rationality? In G. Gigerenzer, \& R. Selten (Eds.), Bounded Rationality: The Adaptive Toolbox (pp. 13-36). Cambridge, MA: The MIT Press.

Simon, H. (1972). Theories of Bounded Rationality. In: C. B. McGuire, \& R. Radner (Eds.), Decisionand Organization (pp. 161-176). Amsterdam: North-Holland.

Simon, H. A. (1982 [1964]). Models of Bounded Rationality. Vol. 2: Behavioral Economics and Business Organization (pp. 405-407). Cambridge, MA: The MIT Press.

Simon, H. A. (1983). Reason in Human Affairs. Stanford, CA: Stanford University Press.

Simon, H. A. (1990). Prediction and Prescription in Systems Modeling. Operations Research, 38, 7-14.

Simon, H. A. (1995). Rationality in Political Behavior. Political Psychology, 16, 45-61.

Simon, H. A. (1996). The Sciences of the Artificial (3rd ed.). Cambridge, MA: The MIT Press. (1st ed., 1969; 2nd ed., 1981)

Simon, H. A. (2001). Science Seeks Parsimony, Not Simplicity: Searching for Pattern in Phenomena. In A. Zellner, H. A. Keuzenkamp, \& M. McAleer (Eds.), Simplicity, Inference and Modelling. Keeping It Sophisticatedly Simple (pp. 32-72). Cambridge: Cambridge University Press. Spanish Version: Simon, H. A. (2007). La Ciencia busca sobriedad, no simplicidad: La búsqueda de pautas en los fenómenos. In W. J. Gonzalez (Ed.), Las Ciencias de Diseño: Racionalidad limitada, predicción y prescripción (pp. 71-107). A Coruña: Netbiblo. 
Scientific Research Publishing (SCIRP) is one of the largest Open Access journal publishers. It is currently publishing more than 200 open access, online, peer-reviewed journals covering a wide range of academic disciplines. SCIRP serves the worldwide academic communities and contributes to the progress and application of science with its publication.

Other selected journals from SCIRP are listed as below. Submit your manuscript to us via either submit@scirp.org or Online Submission Portal.
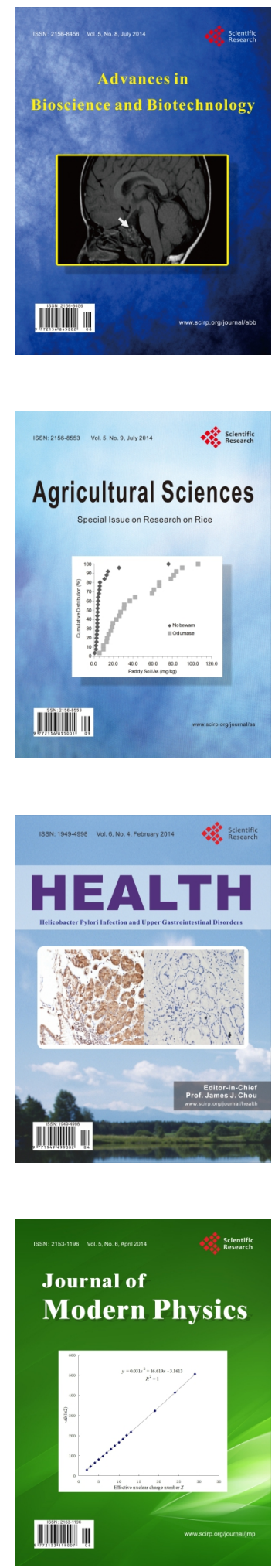
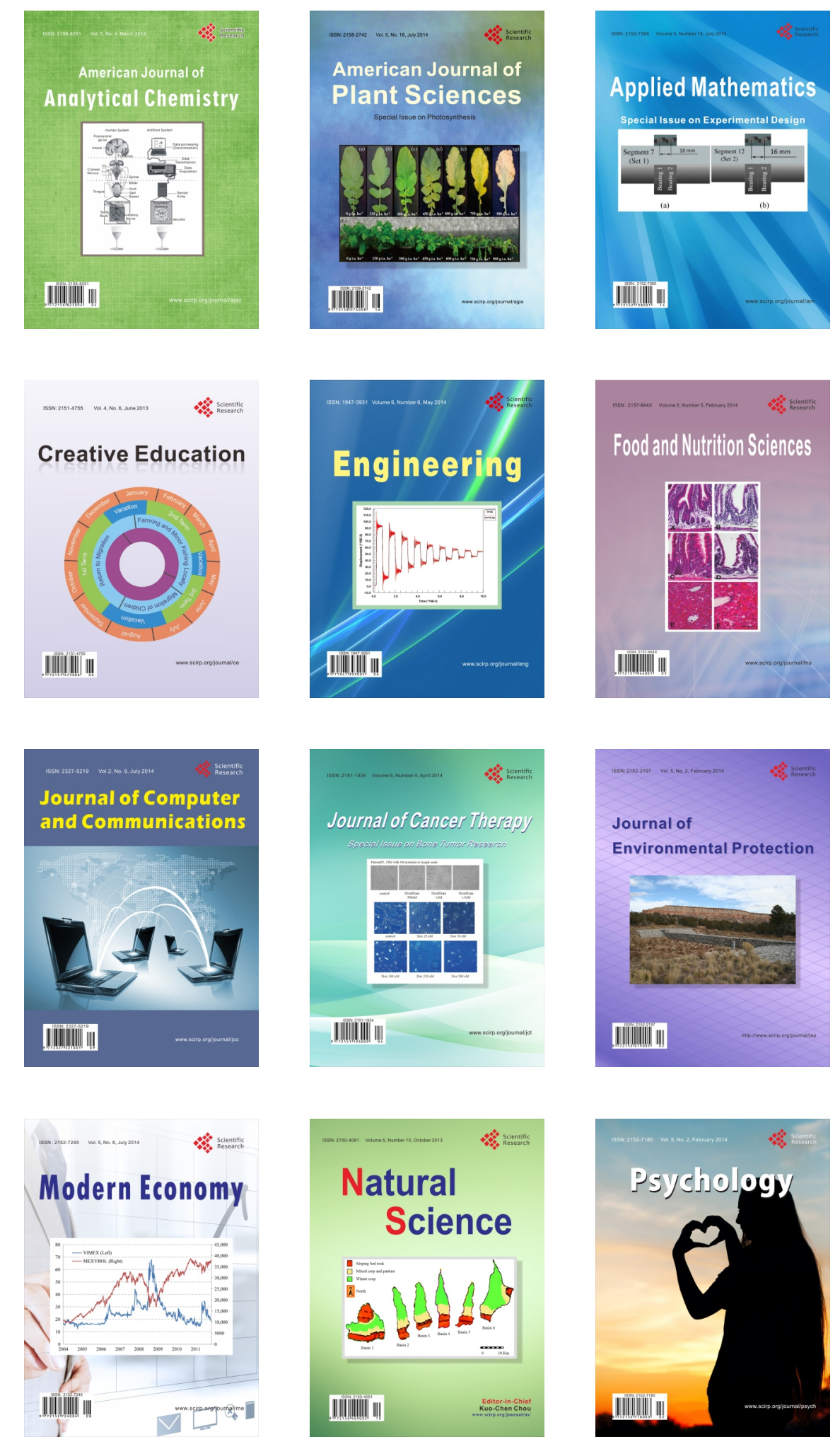